\title{
Left ventricular thrombus
}

\author{
Bernard P Paelinck MD PhD, Christiaan J Vrints MD PhD, Viviane M Conraads MD PhD
}

A

65-year-old man had recurrent angina pectoris eight years after a $Q$ wave anterior myocardial infarction. He had no signs of heart insufficiency. An electrocardiogram showed a sinus rhythm, QS waves in precordial leads and intraventricular conduction delay. Catheterization demonstrated three-vessel coronary artery disease.

He had a dilated left ventricle (end-diastolic volume of $330 \mathrm{~mL}$ ) with severely depressed systolic function (ejection fraction of $22 \%$ ) due to a thin-walled aneurysm (arrowheads in Figure 1) in the anterior and apical segments (Video 1). In these segments, transmural delayed hyperenhancement (arrowheads in Figure 1) was present after an intravenous bolus of $0.2 \mathrm{mmol} / \mathrm{kg}$ gadolinium diethylenetriamine pentaacetic acid. A large mural thrombus was depicted in the left ventricular apex (arrows in Figure 1) (1).

The patient underwent an aneurysmectomy along with coronary artery bypass grafting of the right coronary artery and the circumflex artery. His postoperative course was uneventful and four months later, he was healthy.

\section{REFERENCE}

1. Mollet NR, Dymarkowski S, Volders W, et al. Visualization of ventricular thrombi with contrast-enhanced magnetic resonance imaging in patients with ischemic heart disease. Circulation 2002;106:2873-6.

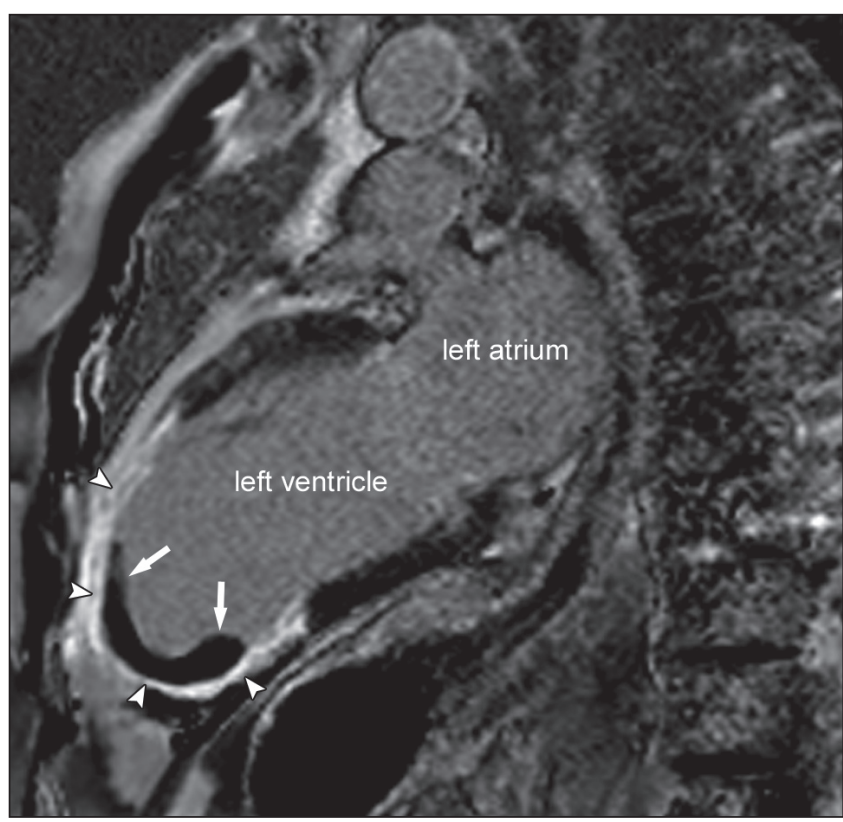

Figure 1

Department of Cardiology, University Hospital Antwerp, Edegem, Antwerp, Belgium

Correspondence: Dr Bernard P Paelinck, Department of Cardiology, University Hospital Antwerp, Wilrijkstraat 10, 2650 Edegem, Antwerp, Belgium.

Telephone +32-3-8214182, fax+32-3-8250848, e-mail bernard.paelinck@uza.be

Received for publication February 5, 2009. Accepted March 23, 2009 